\title{
Progression of Cutaneous Vitiligo in a Patient with Large Posterior Choroidal Melanoma: A Case Report
}

\author{
Angela Ding ${ }^{a}$ Javier Elizalde ${ }^{a-c}$ Rafael Ignacio Barraquer ${ }^{a-c}$ \\ ${ }^{a}$ Centro de Oftalmología Barraquer, ${ }^{b}$ Ocular Oncology Service, and ${ }^{~}$ Universitat \\ Internacional de Catalunya (UIC), Barcelona, Spain
}

\section{Key Words}

Choroidal melanoma · Progression · Cutaneous vitiligo · Pregnancy

\begin{abstract}
Background/Aims: The aim of our study was to report a case of progression of cutaneous vitiligo after large posterior choroidal melanoma diagnosis. Methods: The clinical history, fundus findings and histopathological features suggest the diagnosis of cutaneous vitiligous progression after a diagnosis of large posterior choroidal melanoma. Results: A 30-year-old female, with a personal history of cutaneous vitiligo for 12 years, was diagnosed with choroidal melanoma 18 months previously. The cutaneous vitiligo had progressed over her back, body and arms during the preceding 3 years. She refused treatment because she was in her 28th week of pregnancy. When she came to our clinic her visual symptoms had worsened, and the fundus examination showed a melanocytic choroidal mass. After confirming that there was no extraocular extension, she was treated with enucleation. A histopathological study confirmed the choroidal melanoma diagnosis. Conclusion: The association between the progression of vitiligo and the diagnosis of uveal melanoma could be considered a good prognostic factor, as has been described in cases of cutaneous melanoma. A longer follow-up of these patients will allow us to confirm this association.

(C) 2015 S. Karger AG, Basel
\end{abstract}

\section{Introduction}

Uveal melanoma, the most frequent primary intraocular malignant tumour in adults, usually occurs sporadically [1]. Congenital ocular melanocytosis, which occasionally involves hyperpigmentation of the periorbital skin (oculodermal melanocytosis or naevus 
Ocular Oncology

and Pathology

\begin{tabular}{l|l}
\hline Ocul Oncol Pathol 2015;1:241-247 \\
\hline DOI: 10.1159/000376622 & $\begin{array}{l}\text { @ 2015 S. Karger AG, Basel } \\
\text { www.karger.com/oop }\end{array}$ \\
\hline
\end{tabular}

Ding et al:: Progression of Cutaneous Vitiligo in a Patient with Large Posterior Choroidal Melanoma: A Case Report


Fig. 1. Areas of cutaneous depigmentation (vitiligo) on the upper

thorax and forearms.

\begin{abstract}
of Ota) [2], represents a significant risk factor for the development of uveal melanoma. However, there is very little data in the literature on the relationship between cutaneous depigmentation (vitiligo) and uveal melanoma. Vitiligo is a pathology characterised by areas of depigmentation, often symmetrically distributed, and which tend to increase in size over time [3]. The development of vitiligo in patients with cutaneous melanoma is well known. It has been described that $20 \%$ of patients with cutaneous melanoma present vitiligo and that $1.3 \%$ present vitiligo on the diagnosis of cutaneous melanoma [4]. It is postulated that this relation may be due to the generated immunity to the melanoma antigens, which cross-react with the melanocytes of the normal skin. However, very little information has been published on vitiligo associated with uveal melanoma. We present a clinical case in which cutaneous vitiligo progressed after the diagnosis of choroidal melanoma.
\end{abstract}

\title{
Case Report
}

A 30-year-old Paraguayan woman came to the Ocular Oncology Unit at our centre to request a second opinion regarding a melanoma diagnosed 18 months earlier in her right eye (RE). The patient explained that initially, during a routine check, it was confirmed that she had lost sight in her RE, and the initial diagnosis was a macular subretinal haemorrhage. The patient was 28 weeks pregnant at the time. A month later she was diagnosed with choroidal melanoma, and episcleral brachytherapy was recommended to her after the birth of her baby. The patient rejected the treatment because at that time she was breastfeeding.

At her visit, the patient informed us that the central scotoma had increased over the preceding 2 weeks. Her personal pathological background included a 12-year-old cutaneous vitiligo which had spread to her back, trunk and arms in the previous 3 years (fig. 1). 
Ocular Oncology

and Pathology

\begin{tabular}{l|l}
\hline Ocul Oncol Pathol 2015;1:241-247 \\
\hline DOI: 10.1159/000376622 & $\begin{array}{l}\text { @ 2015 S. Karger AG, Basel } \\
\text { www.karger.com/oop }\end{array}$ \\
\hline
\end{tabular}

Ding et al.: Progression of Cutaneous Vitiligo in a Patient with Large Posterior Choroidal Melanoma: A Case Report

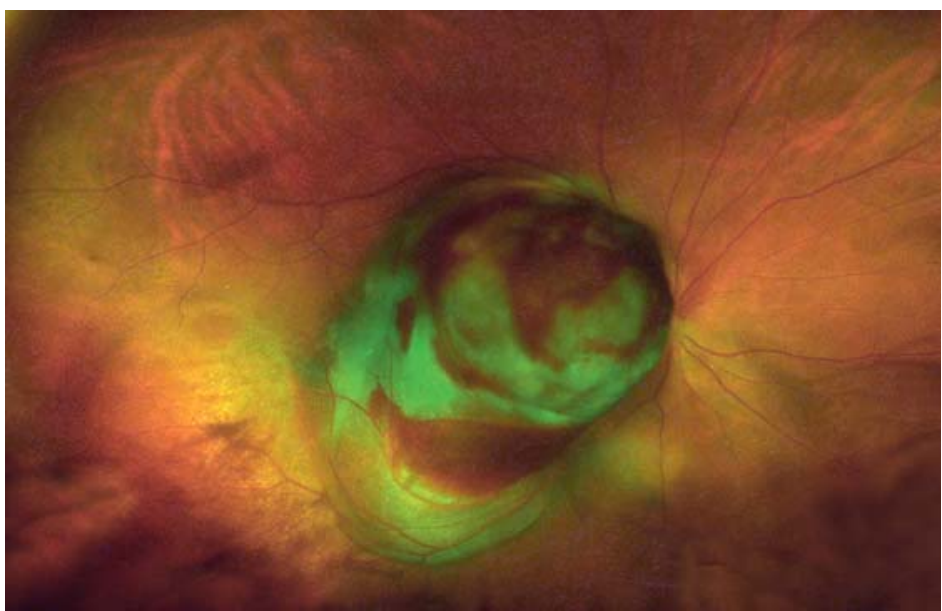

Fig. 2. Melanocytic tumour in the posterior pole, compatible with choroidal melanoma, with rupture of the Bruch membrane and associated haemorrhage (widefield retinography, Optos $^{\circledR}$ 200TX).

The visual acuity in the RE was hand movement, with good light perception and poor light localisation. On examination with a slit lamp, we detected a dark brown iris with no evidence of dilatation of the episcleral vessels (sentinel vessels). With an indirect ophthalmoscope, a melanocytic tumour of the choroid was observed with a prominent mushroom shape with its base affecting the posterior pole. We also detected superficial haemorrhages, presumably related to the highly invasive growth pattern of the tumour (with rupture of the Bruch membrane and possible involvement of the retina), subretinal fluid and haematic remains in the lower vitreous (fig. 2). An examination with B-mode ultrasound (brightness mode) confirmed the presence of a solid tumour in the macular area with a $17.88-\mathrm{mm}$ base and a height of $10.50 \mathrm{~mm}$, compatible with choroidal melanoma associated with exudative retinal detachment and rupture of the Bruch membrane. A-mode ultrasound (amplitude mode) showed the presence of a positive kappa angle (fig. 3). To confirm that there was no extraocular extension, cerebral and orbital magnetic resonance were performed, which confirmed the presence of a hyperintense intraocular mass in the T1-weighted sequences without evidence of a ferromagnetic effect in the T2-weighted images (fig. 4). The left eye had normal visual acuity, and there were no lesions in the fundus. Performing analysis and liver function tests produced no significant findings. We opted to perform enucleation on the affected eye under general anaesthesia, with a 22-mm Medpor (Porex Surgical, Inc.; College Park, Ga., USA) sclera-wrapped implant and suture of the muscles to preserve ocular motility, with very good anatomic results.

Histopathology confirmed the diagnosis of mixed-cell-type choroidal melanoma (with type B fusiform and epithelioid component), with rupture of the Bruch membrane and compression of the optic nerve but with a malignancy-free resection margin. Eighteen mitoses were observed for each 10 high-power fields as well as areas of tumour necrosis (fig. 5). Cytogenetic analysis showed positive hybridization for chromosome 3 monosomy.

\section{Discussion}

Vitiligo affects melanocytes in the stratum basale of the epidermis, and its prevalence in the world population is estimated at $0.5-1 \%$ [5]. There is a frequent association between vitiligo and cutaneous melanoma, especially among patients who develop metastasis [6]. This association is probably due to an immune response to the melanoma antigens, which destroys the subject's normal melanocytes and reduces the growth of malignant melanocytes [7]. Therefore, in cases of cutaneous melanoma, vitiligo could be considered a good prognostic factor [8]. It has been shown that patients with vitiligo and residual melanoma or those who develop metastasis have a greater survival rate than expected [4, 9].

In the literature, there have been very few cases of vitiligo described in patients with uveal melanoma. In 1968, Nirankari et al. [1] discussed the case of a 57-year-old man who 
Ocular Oncology and Pathology

Fig. 3. B-mode ultrasound showing the presence of solid choroidal tumour with diffuse and cupuliform growth, base $17.88 \mathrm{~mm}$ and height $10.04 \mathrm{~mm}$.

\begin{tabular}{l|l}
\hline Ocul Oncol Pathol 2015;1:241-247 \\
\hline DOI: 10.1159/000376622 & $\begin{array}{l}\text { @ 2015 S. Karger AG, Basel } \\
\text { www.karger.com/oop }\end{array}$ \\
\hline
\end{tabular}

Ding et al.: Progression of Cutaneous Vitiligo in a Patient with Large Posterior Choroidal Melanoma: A Case Report
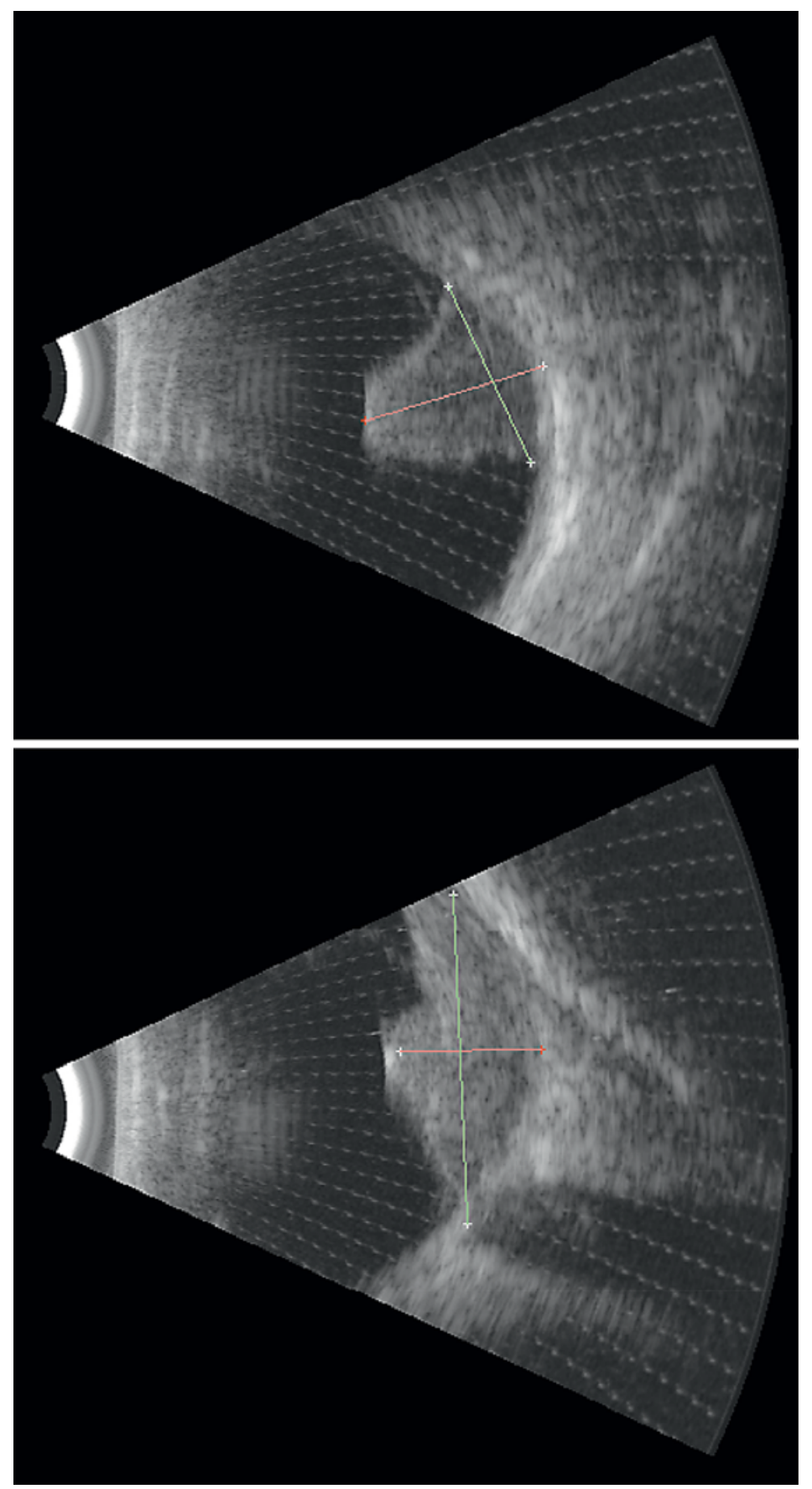

underwent evisceration for panophthalmitis, but uveal melanoma was not detected. Seven years later, he developed multiple patches of vitiligo and 2 years later, he had what was presumed to be a relapse of the melanoma with orbital extension. In 1982, Albert et al. [4] described the 2 following cases: the first was a 69-year-old man who 5 years after being enucleated for a $15 \times 7 \times 7 \mathrm{~mm}$ uveal melanoma with associated retinal detachment showed symptoms of cutaneous depigmentation on the arms, which spread to the backs of his hands and fingers. The second case developed halo naevus on the trunk and limbs a year after being 
Ocular Oncology

and Pathology

\begin{tabular}{l|l}
\hline Ocul Oncol Pathol 2015;1:241-247 \\
\hline DOI: 10.1159/000376622 & $\begin{array}{l}\text { @ 2015 S. Karger AG, Basel } \\
\text { www.karger.com/oop }\end{array}$ \\
\hline
\end{tabular}

Ding et al.: Progression of Cutaneous Vitiligo in a Patient with Large Posterior Choroidal Melanoma: A Case Report

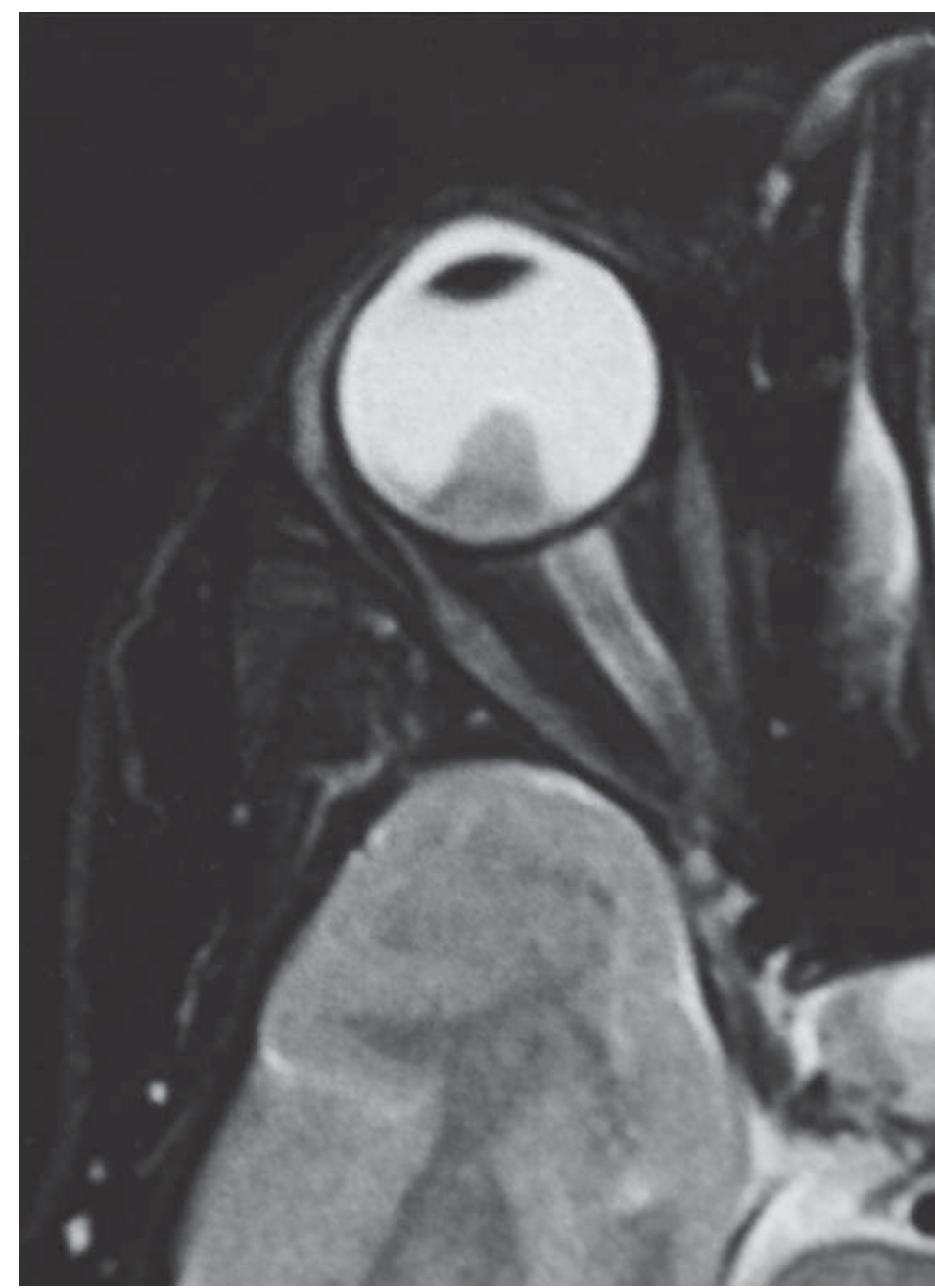

Fig. 4. T2-weighted orbital magnetic resonance showing the hyperintense tumour mass located on the posterior pole of the RE. 
Ocular Oncology and Pathology

Fig. 5. a Macroscopic appearance of the tumour: a $18 \times 15 \mathrm{~mm}$ brown-black mushroom-shaped mass. b Microscopic analysis: 18 mitoses for each 10 high-power fields. Intra-tumour lymphocytes were not identified and approximately $1 / 3$ of the tumour is accompanied by a large amount of melanin pigment.

\begin{tabular}{l|l}
\hline Ocul Oncol Pathol 2015;1:241-247 \\
\hline DOI: 10.1159/000376622 & $\begin{array}{l}\text { (c) 2015 S. Karger AG, Basel } \\
\text { www.karger.com/oop }\end{array}$ \\
\hline
\end{tabular}

Ding et al.: Progression of Cutaneous Vitiligo in a Patient with Large Posterior Choroidal Melanoma: A Case Report
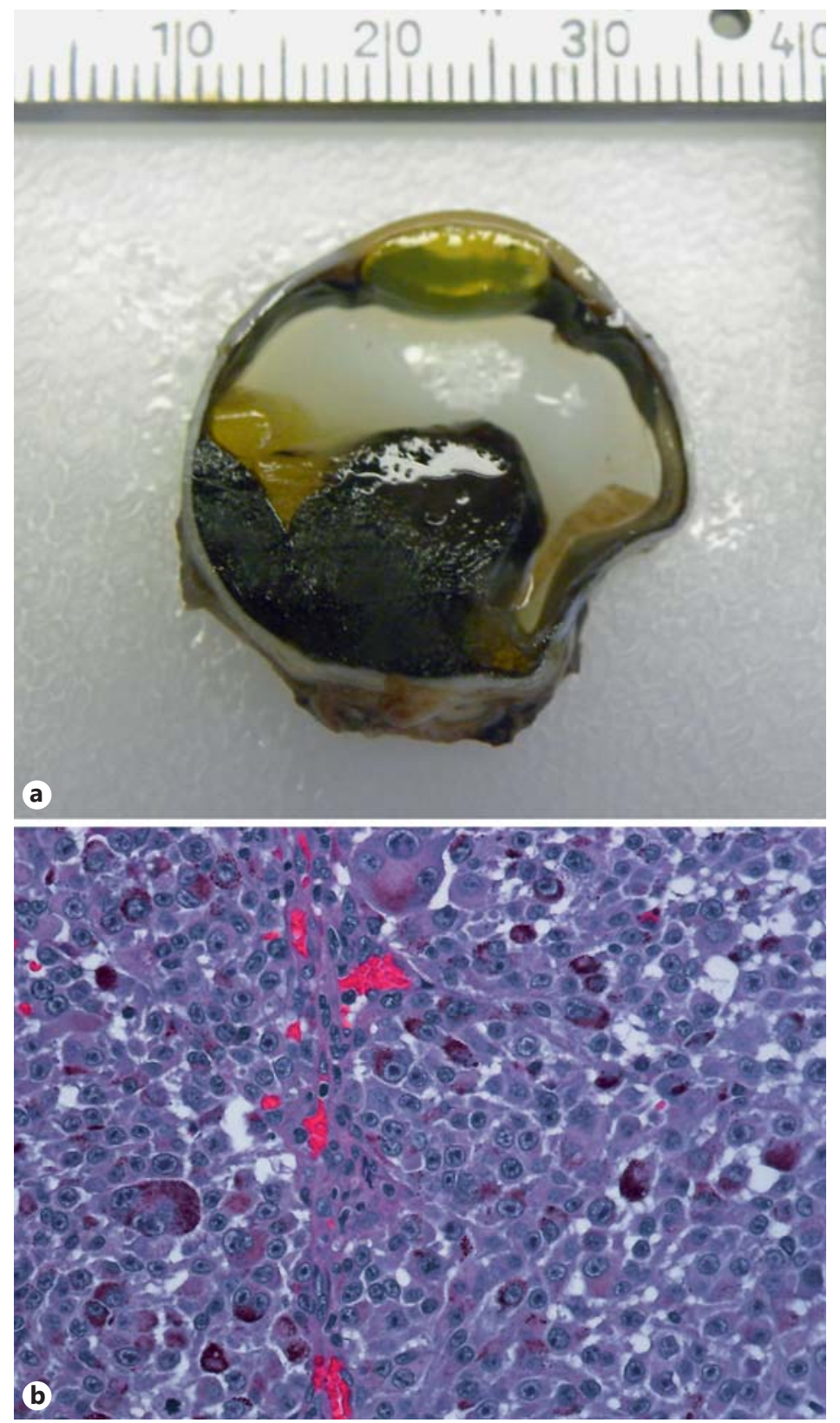

The exact prevalence of vitiligo in patients with uveal melanoma is unknown [4]. Likewise, it is not known whether this association or the progression of vitiligo prior to the diagnosis of uveal melanoma can be considered a good prognostic factor as has been described in cases of cutaneous melanoma. There is undoubtedly a need to prolong the time spent monitoring sporadic cases with associated uveal melanoma and vitiligo in order to determine its influence on survival rates. 
Ding et al.: Progression of Cutaneous Vitiligo in a Patient with Large Posterior Choroidal Melanoma: A Case Report

\section{References}

1 Nirankari MS, Khanna KK, Mathur RP: Uveal malignant melanoma with leucoderma. J All India Ophthalmol Soc 1968;16:63-66.

2 Frezzotti R, Guerra R, Dragoni GP, Bonanni P: Malignant melanoma of the choroid in a case of naevus of ota. Br J Ophthalmol 1968;52:922-924.

3 Chang MA, Fournier G, Koh HK, Sober AJ, Nakagawa H, Fitzpatrick TB, Albert DM: Ocular abnormalities associated with cutaneous melanoma and vitiligo like leukoderma. Graefes Arch Clin Exp Ophthalmol 1986;224: 529-535.

4 Albert DM, Todes-Taylor N, Wagoner M, Nordlund JJ, Lerner AB: Vitiligo or halo nevi occurring in two patients with choroidal melanoma. Arch Dermatol 1982;118:34-36.

5 Tarlé RG, Nascimento LM, Mira MT, Castro CC: Vitiligo - part 1. An Bras Dermatol 2014;89:461-470.

6 Nordlund JJ, Kirkwood JM, Forget BM, Milton G, Albert DM, Lerner AB: Vitiligo in patients with metastatic melanoma: a good prognostic sign. J Am Acad Dermatol 1983;9:689-696.

7 Ram M, Shoenfeld Y: Harnessing autoimmunity (vitiligo) to treat melanoma: a myth or reality? Ann NY Acad Sci 2007;1110:410-425.

8 Quaglino P, Mrenco F: Vitiligo is an independent favourable prognostic factor in stage III and IV metastatic melanoma patients: results from a single-institution hospital-based observational cohort study. Ann Oncol 2010;21:409-414.

9 Bystryn JC, Rigel D, Friedman RJ, Kopf A: Prognostic significance of hypopigmentation in malignant melanoma. Arch Dermatol 1987;123:1053-1055.

10 Rishi P, Shields CL, Patrick K, Shields JA: Cutaneous vitiligo following management of uveal melanoma in 6 patients. JAMA Ophthalmol 2013;131:1174-1178. 